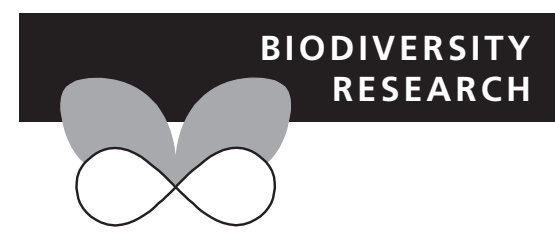

\title{
Climate change-induced decline in bamboo habitats and species diversity: implications for giant panda conservation
}

\author{
Renqiang $\mathrm{Li}^{1}$, Ming $\mathrm{Xu}^{2 \star}$, Michelle Hang Gi Wong ${ }^{1}$, Shuai Qiu ${ }^{1,3}$, \\ Qingkai Sheng ${ }^{1}$, Xinhai $\mathrm{Li}^{4}$ and Zengming Song ${ }^{5}$
}

${ }^{1}$ Key Laboratory of Ecosystem Network Observation and Modeling, Institute of Geographic Sciences and Natural Resources, the Chinese Academy of Sciences, Beijing, China, ${ }^{2}$ Department of Ecology, Evolution and Natural Resources, Rutgers University, New Brunswick, NJ 08901, USA, ${ }^{3}$ University of Chinese Academy of Sciences, Beijing, China, ${ }^{4}$ Key Laboratory of the Zoological Systematics and Evolution, Institute of Zoology, the Chinese Academy of Sciences, Beijing, China, ${ }^{5}$ PRC-GEF Partnership on Land Degradation in Dryland Ecosystems, Beijing, China

${ }^{*}$ Correspondence: Ming Xu, Department of Ecology, Evolution and Natural Resources, Rutgers University, New Brunswick, NJ 08901, USA.

E-mail: mingxu@crssa.rutgers.edu

\begin{abstract}
Aim Conservation strategies must anticipate how climate change may alter the geographic distributions of limited food resources for highly specialized species. Here, we use bamboo as a case study to investigate climate change-induced changes in species diversity and discuss how to protect the critical food species for giant pandas.
\end{abstract}

Location Giant panda habitats.

Methods Using a niche-based model and the most updated climate projections, we projected the current and future distribution of 16 bamboo species under no and universal dispersal assumptions. We then assessed the impact of climate change on bamboo forests and their alpha and beta diversities in the giant panda habitats and reserves.

Results Under both dispersal assumptions and three RCPs, six bamboo species are projected to vanish from panda habitats as climate change progresses, resulting in a great loss of the current bamboo forests. Although about half of the bamboo species may potentially colonize new climatically suitable areas under universal dispersal, the other species would experience significant habitat loss. Consequently, climate change would reduce both the alpha and beta diversity of bamboo species in panda habitats. Meanwhile, the proportion of single-species bamboo forests would significantly increase. The decline in bamboo forests and diversity would be most drastic in Qinling, Daxiangling and Qionglaishan Mountains, whereas those in the north-west of Minshan Mountains and Liangshan Mountains may increase.

Main conclusions Climate change-induced decline in bamboo habitats and species diversity would pose a severe challenge to the food availability of giant pandas. We posit that human-assisted adaptation and increasing bamboo species diversity are critical to ensuring food security of the giant panda in a changing climate. Our results indicate that conservation planning should not only incorporate species range shifts but also diversity patterns in communities under climate change.

\section{Keywords}

Bamboo species, climate change, MAXENT, panda conservation, species diversity.

\section{INTRODUCTION}

Rapid climate change is already having profound impacts on global biodiversity (Bellard et al., 2012) and may become increasingly prominent relative to the other environmental factors, such as habitat destruction, fragmentation and biological invasion (Yang \& Xu, 2003; Thomas et al., 2004; Thuille, 2007). Some simulation studies and field observations strongly suggest that many species are already responding to recent global warming with expansion or contraction 
in range, and this process is likely to continue as climate change progresses (Walther et al., 2002; MacLean \& Wilson, 2011; Ponce-Reyes et al., 2013). Some species would be able to adapt to climate change by migrating to new climatically suitable areas, while those that are unable to do so would be locally extirpated; therefore, species with poor dispersal ability are particularly vulnerable (Thuiller et al., 2005; Chen et al., 2011; MacLean \& Wilson, 2011). Climate change-induced species range shifts will alter the distribution of biodiversity and cause a change in species diversity (Menendez et al., 2007), because species diversity in communities in coming decades will be determined by the balance between species habitat gain and loss (Gallagher et al., 2013). Combining future climate change scenario and niche-based models, many studies have found that climate change would threaten species diversity for both plant (Bakkenes et al., 2002; Thuiller et al., 2005; Golicher et al., 2012) and animal communities (Araújo et al., 2006; Kissling et al., 2010). The spatial pattern changes of species diversity are expected to affect community composition and structure, with important consequences for ecosystem function (Wardle et al., 2011), which will pose a severe challenge to biodiversity conservation in future. Thus, a major task for conservation planning is to predict possible consequences of climate change, and based on these propose adaptation and mitigation measures (Wiens \& Graham, 2005; Araújo \& Rahbek, 2006; Schwartz et al., 2006).

Many modelling approaches, including process-based and niche-based models, have been developed to explore the effects of climate change on species ranges and diversity (Heikkinen et al., 2006; Mokany \& Ferrier, 2011). Processbased models project vegetation distributions, biomass and primary production at continental or global scales by simulating natural processes, but they require large amounts of empirical data for parameterization and validation, which restricts their wide applications for some specific species or regions (Pearson \& Dawson, 2003; Thuiller et al., 2006a,b). On the other hand, niche-based models project species distributions by analyzing the relationships between species distributions and a number of environmental variables (Synes \& Osborne, 2011). Although these relatively simple models may under-represent complex natural systems by neglecting competitive interactions, species plasticity, adaptation and time-lag (Davis et al., 1998; Hannah et al., 2002; Pearson \& Dawson, 2003), with a good understanding of the modelling techniques, and appropriate model validation and testing, they can be regarded as the primary tools for projecting species range shifts and extinction risk, evaluating conservation priorities and assessing reserve designs (Araújo \& Williams, 2000; Akcakaya et al., 2006; Hijmans \& Graham, 2006; Gallagher et al., 2013; Duckett et al., 2013).

Most species distribution models (SDMs) mainly rely on climatic factors to predict the geographic distribution of species. However, recent studies emphasized that some important environmental factors and species characteristics may be critical to improve the predictive power of SDMs (Boulangeat et al., 2012; Grassein et al., 2014). New advances in this field have started to develop species modelling approaches by incorporating more factors and parameters, such as metapopulation demography and landscape interactions (Keith et al., 2008; Vos et al., 2008), species life history traits (Peery et al., 2006), biotic interactions (Preston et al., 2008), species dispersal ability (Duckett et al., 2013), species evolution and adaptation (Byrne 2008) and human activities and disturbances (Midgley et al., 2003; Thuiller et al., 2004). For example, inclusion of biotic interactions with other species in SDMs is expected for long-term prediction of climate change-induced species range shifts, particularly for species strongly dependent on biotic interactions (Brooke et al., 2012). Thuiller et al. (2004) found that the inclusion of land cover significantly improved the explanatory power of bioclimatic models and the most relevant variables across groups were those not explained or poorly explained by climate over Europe. Incorporating phylogeography and landscape genetics into SDMs can be used to address climate adaptation (Scoble \& Lowe, 2010). The main aim of these studies focused on how to provide more robust evidence for species conservation and management in future.

The giant panda, a conservation icon, feeds almost exclusively on bamboo. Human destruction to the bamboo forests is one of the major causes of the drastic reduction in the number and distribution of giant pandas in the past decades (Liu et al., 2001; Loucks et al., 2001; Shen et al., 2008; Ran et al., 2009). Understanding how climate change will affect these bamboo communities that provide food sources is extremely critical for developing effective conservation strategies in future (Fan et al., 2014). Bamboo are colonial species that mainly reproduce asexually by growing new shoots out of their rhizomes; thus, their dispersal ability is extremely poor, of no more than $6 \mathrm{~m}$ per year (Fan, 1999). Many of the bamboo species consumed by giant pandas are found to be sensitive to climate change (Qing, 1989). A recent study finds that three dominant bamboo species would face a substantial reduction in the distributional ranges during the 21st century in the Qingling Mountains (Tuanmu et al., 2013). However, the potential consequences of climate change on bamboo species distributions in other regions and species diversity in entire giant panda habitats remain exclusive, which is required for the design of an effective conservation network for panda conservation under climate change.

The aim of this study is to investigate climate changeinduced changes of bamboo species range and spatial diversity patterns in giant panda habitats. Using three of the most recently developed Representative Concentration Pathways (RCP 2.6, 4.5 and 8.5), five climate models (CCSM4, CNRM-CM5, HadGEM-ES, MIROC5 and MPI-ESM-LR) and niche-based modelling techniques, we projected the potential geographic distribution of 16 bamboo species eaten by giant pandas to the year 2070 in the entire giant panda habitats. We assessed the potential impact of climate change on bamboo forests and bamboo species diversity in panda habitats and reserves and discussed the implications of these results on giant panda conservation in a changing climate. 


\section{METHODS}

\section{Study area and data}

The geographic distribution of 16 bamboo species (Table S1 in Supporting Information) was obtained from the Third National Survey on Giant Pandas (State Forestry Administration, 2006). They account for more than $95 \%$ of the total area of bamboo forests in the panda habitats. The survey of 16 bamboo species was conducted using line transect and sampling methods in 57 counties in six mountains in Sichuan, Shaanxi and Gansu provinces during 1999-2001. The line transects were selected on a topographic map of 1:50,000 or $1: 100,000$, and one transect was placed per 800 ha in key areas and one per 2400 ha in other areas. The transects extend from low to high altitudes on mountain slopes, taking into account the spatial distributions of bamboo species and giant pandas. Along each transect, no less than four $20 \times 20 \mathrm{~m}^{2}$ plots were set up and surveyed. There were altogether 11,174 line transects sampled in this survey. We randomly obtained a total of 5981 presence data for the 16 bamboo species from their distribution area for model building.

The survey showed that the wild population of giant pandas comprised of 1596 individuals (Table S2) in six mountain ranges. To reduce edge effects and accommodate potential changes of bamboo distribution under climate change, the simulation area included all adjacent counties surrounding these 57 counties, resulting in a total of 135 counties (Fig. 1). Another independent dataset of 1820 records on seven bamboo species in the Daxiangling Mountains from a most recent field survey was also used for the model evaluation. To explore the change of bamboo distribution within panda reserves under climate change, the boundaries of 40 nature reserves were supplemented by data from $\mathrm{Wu}$ et al. (2011), resulting in 59 nature reserves in total (Fig. 1). Although more than 60 nature reserves in China have been established to protect the giant panda, a few of them that are county-level reserves have unclear boundaries or no boundary data at all. Given that the areas of these reserves are small, we considered them insignificant to the overall results of the study.

A set of 19 bioclimatic variables (Table S3) at 30 s resolution were collected from the WorldClim dataset for current (average for 1951-2000) and future climate conditions in 2070 (average for 2061-2080; Hijmans et al., 2005). We adopted five general circulation models (GCMs; CCSM4, CNRM-CM5, HadGEM2-ES, MIROC5 and MPI-ESM-LR), under three IPCC-CMPI5 RCPs $(2.6,4.5$ and 8.5) to test the impacts of different climate change scenarios on bamboo and better capture the range of uncertainty. To minimize collinearity between these bioclimatic variables, we calculated intercorrelations among 2 of the 19 bioclimatic variables, and one of the variables was removed when the correlation coefficient $>|0.70|$. Our method for selecting predictor was very similar to Tuanmu et al. (2013). As a result, eight bioclimatic variables (Bio 2, Bio 4, Bio 10, Bio 11, Bio 15, Bio 17, Bio 18 and Bio 19; Table S3) were used to construct our models.

\section{Species distribution modelling and testing}

We applied a maximum entropy modelling technique with the MaxEnt software (Phillips et al., 2006), which has been extensively adopted to project species range shifts and change in species diversity patterns under climate change (Pearson et al., 2007; Ponce-Reyes et al., 2012; Wong et al., 2013).We first built bamboo species models with presence data and the selected eight bioclimatic variables. Models were constructed with the software MAxEnT in default settings with a
Figure 1 Location of study area, covering six mountain ranges (Qingling, Minshan, Qionglaishan, Daxiangling, Xiaoxiangling and Liangshan Mountain Ranges) in Sichuan, Shaanxi and Gansu Provinces of China. The elevation of this study area ranges from 273 to $6298 \mathrm{~m}$.

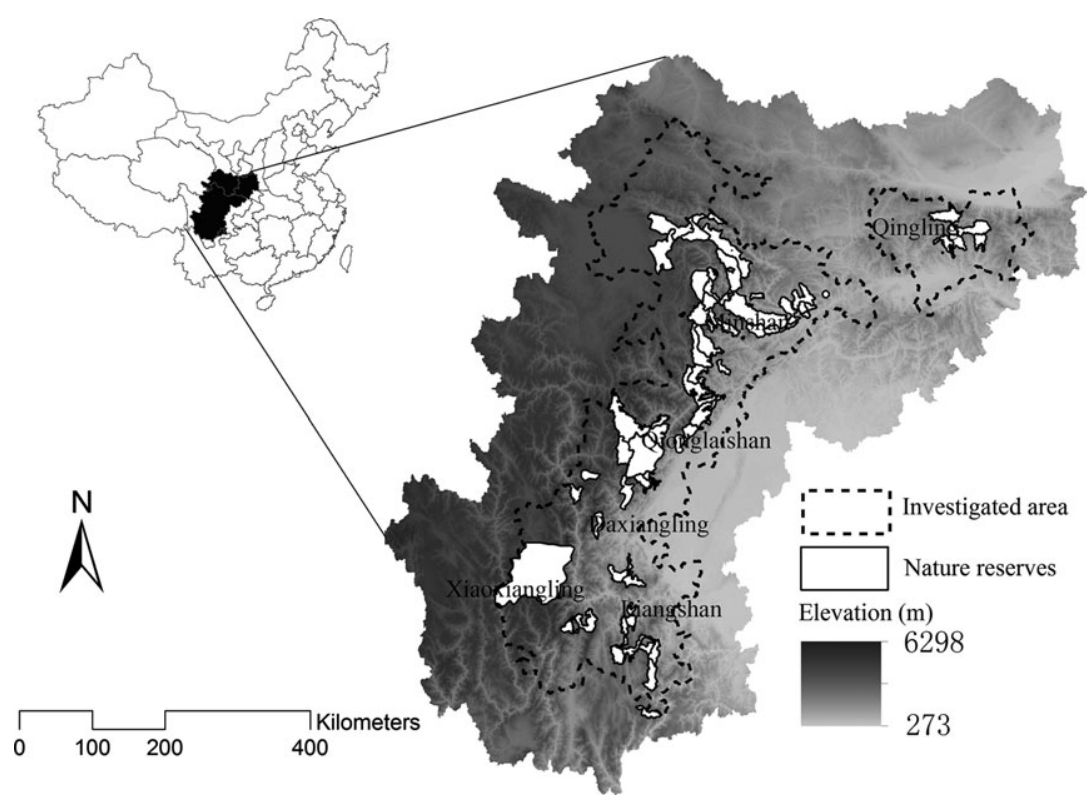


maximum of 500 iterations. We performed a test according to the method of VanDerWal et al., 2009; we extracted background data from (1) the entire study area, (2) the area covered by the Third National Survey and (3) area (1) minus area (2) of above and compared the performance of these models. The results indicated that model performance is the highest when background data were selected from the entire study area. Therefore, the entirety of the study area was used as a background from which pseudo-absences were drawn to improve model performance. We performed 10 replications for each bamboo species, using cross-validation procedures where we divided our dataset using $75 \%$ of the data for model calibration and retaining $25 \%$ of the data to evaluate models. In response to criticisms to the use of the area under the receiver operating characteristic (ROC) curve (AUC) in the species distribution modelling (Lobo et al., 2008; Li \& Guo, 2013), we assessed model performance with both average AUC and the relative importance of commission and omission. AUC provides a single measure of model performance and ranges from 0.5 (randomness) to 1 (perfect discrimination), where a score higher than 0.7 is considered a good model performance (Fielding \& Bell, 1997; Rebelo et al., 2010). As AUC is not appropriate to evaluate the accuracy of binary predictions, we also used true skill statistic (TSS) as suggested by recent studies (Lobo et al., 2008; Li \& Guo, 2013) to assess the accuracy of the bamboo species models. The TSS takes into account both omission and commission errors, and success as a result of random guessing, and ranges from -1 to +1 , where +1 indicates perfect agreement and values of zero or less indicate a performance no better than random. It is a simple and intuitive measure for the performance of species distribution models when predictions are expressed as presence-absence maps (Allouche et al., 2006). We then ran the model with future bioclimatic variables to simulate the future suitability of bamboo species under the three RCPs. To represent the slight variability inherent in our ensemble of different GCM models, the occurrence probability of each bamboo species is expressed as the range (minimum, average and maximum) across the five GCMs and 10 model replicates. As all ensembles produced qualitatively and quantitatively similar results (Figure S1), for clarity we present only the averaged outputs under three RCPs to form ensembled forecasts of occurrence probability of the bamboo species (Araújo \& New, 2007). However, we also presented the results using minimum and maximum probability of each bamboo species as supporting information, to capture the uncertainty associated with different projections in future climate conditions. To interpret these ensembled forecasts of occurrence probability to presence-absence distribution maps for each bamboo species, we defined the average threshold with a value corresponding to a $10 \%$ omission error (Tuanmu et al., 2013). We analyzed future species distributions with two assumptions of species dispersal (no dispersal and universal dispersal; Peterson et al., 2002). Universal dispersal means that species could disperse to any suitable places for population persistence in future. No dispersal means that species only can inhabit only places that are modelled to be suitable both in the present and in future.

\section{Spatial pattern of alpha and beta diversity}

Species richness, hereafter alpha diversity, was generated by calculating the number of species present in each $1-\mathrm{km}^{2}$ grid cell across the entire study region based on the binary distribution maps produced for the 16 bamboo species. We followed Ochoa-Ochoa et al.'s (2012) suggestion to calculate beta diversity by means of a moving window performed using a nine-pixel window size. Beta diversity was estimated using Whittaker's classic formula, $\beta w=\gamma /$ mean $\alpha$, where $\gamma$ (gamma diversity) is the total number of species in our moving window and mean $\alpha$ is the arithmetic mean of alpha diversity of all the pixels within the window. This classic formula was chosen as it is not sensitive to contrasting values of gamma diversity (Srivastava, 1999) and also because of its straightforward interpretation.

Both alpha and beta diversity can change with the thresholds and window sizes selected, so we set different moving windows $\left(9,16\right.$ and $\left.25 \mathrm{~km}^{2}\right)$ to test the sensitivity of results. The two metrics from different window size produced qualitatively similar results about the impact of climate change on change patterns of species diversity. For clarity, we report results for the $9 \mathrm{~km}^{2}$ window size only, because our main purpose of this study is to assess how the spatial patterns of these metrics may change as future climate change in the study region, rather than testing the effects of similarity due to distance and calculating the values of species diversity.

The spatial distribution of bamboo forests was mapped where at least one bamboo species was projected to occur. The spatial distribution patterns of alpha and beta diversity were mapped for three RCPs and for the current and future (2070). We then obtained their potential change of species diversity in bamboo forests by overlapping their current and future maps and identifying areas where diversity are projected to be stable, increased or decreased under climate scenarios. We also overlaid these projected distribution maps with the boundaries of 59 nature reserves to explore their change of distribution within these panda reserves under climate change.

\section{RESULTS}

\section{Accuracy of species distribution models}

All models for the 16 bamboo species perform well, with high-average AUC scores and low omission rates (OR) at the $10 \%$ cumulative threshold value (Table S1). The trends of AUC scores for these models generally agree with those for test gain (the relative contribution of the environmental variables to the niche models), indicating that all models had a high level of accuracy. The high TSS scores of these models also suggested that only a small percentage of test points fell outside the area predicted as 'presence', and our projections 
have high accuracy (Table S1). Moreover, the average rate of correct simulation of 1820 independent presence data points was 0.90 , which also supports that our models have reasonably captured the relationships between species occurrence and climate conditions and can be used to simulate species distributions for current and future conditions.

\section{Potential bamboo species range shifts under climate change}

Our results projected by the three RCPs suggest that bamboo species in giant panda habitats would be threatened by future climate change. Under the assumption of no dispersal, all of the 16 bamboo species are projected to reduce their current suitable habitats, and nearly half of the species would lose over $50 \%$ of their current habitats under the three RCPs by 2070 (Table 1). Under the assumption of universal dispersal, the impacts of climate change could be less severe. Nevertheless, about half of the species would still suffer from habitat contraction, of which, up to six species would suffer habitat reduction of more than $50 \%$ (Table 1). The projections under the two dispersal assumptions showed that some of the 16 bamboo species may completely vanish from the current giant panda habitats, species such as Bashania fargesii, Fargesia qinlingensis, Bashania fangiana, Chimonobambusa szechuanesis, Yushania brevipaniculata and Fargesia robusta. These species are now distributed mainly in the Qingling, Qionglaishan and Liangshan Mountains. Under the assumption of universal dispersal, about half of 16 species could colonize new climatically suitable areas in the north-west part of the Minshan Mountains and Liangshan Mountains. The species with the most habitat gain included Yushania ailuropodina, Yushania maculate, Fargesia denudate, Yushania glauca, Yushania lineolata and Fargesia demudata (Figure S1).

\section{Potential changes in bamboo forest area}

Future climate change could significantly reduce the distributional area of bamboo forests in giant panda habitats

Table 1 The number of bamboo species that may experience different levels of bamboo habitat change projected under the two dispersal assumptions (no dispersal and universal dispersal) by 2070 under RCP 2.6, 4.5 and 8.5

\begin{tabular}{|c|c|c|c|c|c|c|}
\hline \multirow{3}{*}{$\begin{array}{l}\text { Percentage of } \\
\text { habitat change } \\
(\delta \%)\end{array}$} & \multicolumn{3}{|c|}{ No dispersal } & \multicolumn{3}{|c|}{ Universal dispersal } \\
\hline & $\mathrm{RCP}$ & $\mathrm{RCP}$ & $\mathrm{RCP}$ & RCP & RCP & RCP \\
\hline & 2.6 & 4.5 & 8.5 & 2.6 & 4.5 & 8.5 \\
\hline$\delta=-100$ & 1 & 4 & 5 & 1 & 3 & 5 \\
\hline$-100<\delta \leq-50$ & 6 & 3 & 4 & 5 & 4 & 3 \\
\hline$-50<\delta \leq 0$ & 9 & 9 & 7 & 3 & 1 & 1 \\
\hline $0<\delta \leq 50$ & 0 & 0 & 0 & 5 & 5 & 3 \\
\hline $50<\delta \leq 100$ & 0 & 0 & 0 & 0 & 1 & 1 \\
\hline$\delta>100$ & 0 & 0 & 0 & 2 & 2 & 3 \\
\hline Total & 16 & 16 & 16 & 16 & 16 & 16 \\
\hline
\end{tabular}

(Fig. 2a-f). Under the assumption of universal dispersal, the total bamboo forest area would see a net reduction of $9-22 \%$ by 2070 (Table 2), where $30-48 \%$ of the current bamboo forest would disappear under the future climate. Meanwhile, new climatically suitable areas for bamboo forests would also be created, covering an area of about $22-26 \%$ of the current bamboo forest. Spatially, climate change would induce bamboo forest loss most prominently in Qinling, Daxiangling and Qionglaishan Mountains, while it would facilitate bamboo forest development in the Liangshan Mountains, the north-west part of the Minshan Mountains and Xiaoxiangling Mountains (Fig. 2a-f).

\section{Potential changes in bamboo species diversity}

The current spatial pattern of alpha diversity shows a general reduction from the central to peripheral areas (Figure S2). The maximum value is seven and is found to occur in the Xiaoxiangling and Minshan Mountains. Under future climate conditions, however, alpha diversity is predicted to reduce severely and widely by 2070 (Fig. 2). The maximum value of alpha diversity would reduce to four or five under different RCP and dispersal assumption (Figure S3). Under the assumption of no dispersal, it is projected to decrease by $59 \%, 62 \%$ and $68 \%$ of the current bamboo forest by 2070 for the three RCP climate scenarios (2.6, 4.5 and 8.5), respectively. The percentage of bamboo forests that may experience over $50 \%$ decline in alpha diversity would be $50 \%, 56 \%$ and $63 \%$ for the three RCPs (Figs $2 a-c$ \& $4 a$ ). Under the assumption of universal dispersal, $31-36 \%$ of total bamboo forest (including newly gained and current bamboo forests) may increase in alpha diversity, while $52-63 \%$ of the current bamboo forest may decline in alpha diversity by 2070 (Figs 2d-f \& 4b). Moreover, the proportion of singlespecies bamboo forests in the total bamboo forests by area for no dispersal would increase from the current $40 \%$ to $55 \%, 51 \%$ and $54 \%$ by 2070 for RCP 2.6, 4.5 and 8.5, respectively. Even under the assumption of universal dispersal, it would still rise to $49 \%, 47 \%$ and $48 \%$ for the three RCPs (Figure S3).

The beta diversity of bamboo species would also decline under three RCPs in most of our study area (Fig. 3; Figure S4). For the assumption of no dispersal, between now and 2070, beta diversity would increase in 19-26\% of current bamboo forests, while decreases will occur in $46-61 \%$ (Figs $3 \mathrm{a}-\mathrm{c} \& 4 \mathrm{c}$ ). For universal dispersal, the percentage of the current bamboo forests with declines in beta diversity would increase as time progresses (Figs $3 \mathrm{~d}-\mathrm{f}$ \& 4d). The bamboo species diversity (alpha and beta), in general, would significantly decline in the giant panda habitats under future climate change. The greatest decrease in species diversity would be principally concentrated in the Qingling Mountains, the northern part of Daxiangling Mountains and the Qionglai Mountains (Figs $2 \& 3$ ). 
(a) No dispersal + RCP 2.6

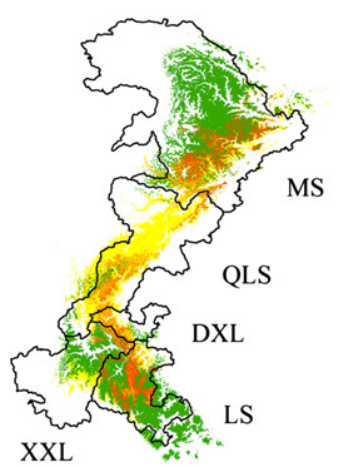

(b) No dispersal + RCP 4.5

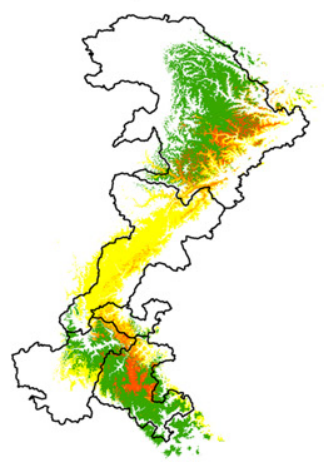

(c) No dispersal + RCP 8.5
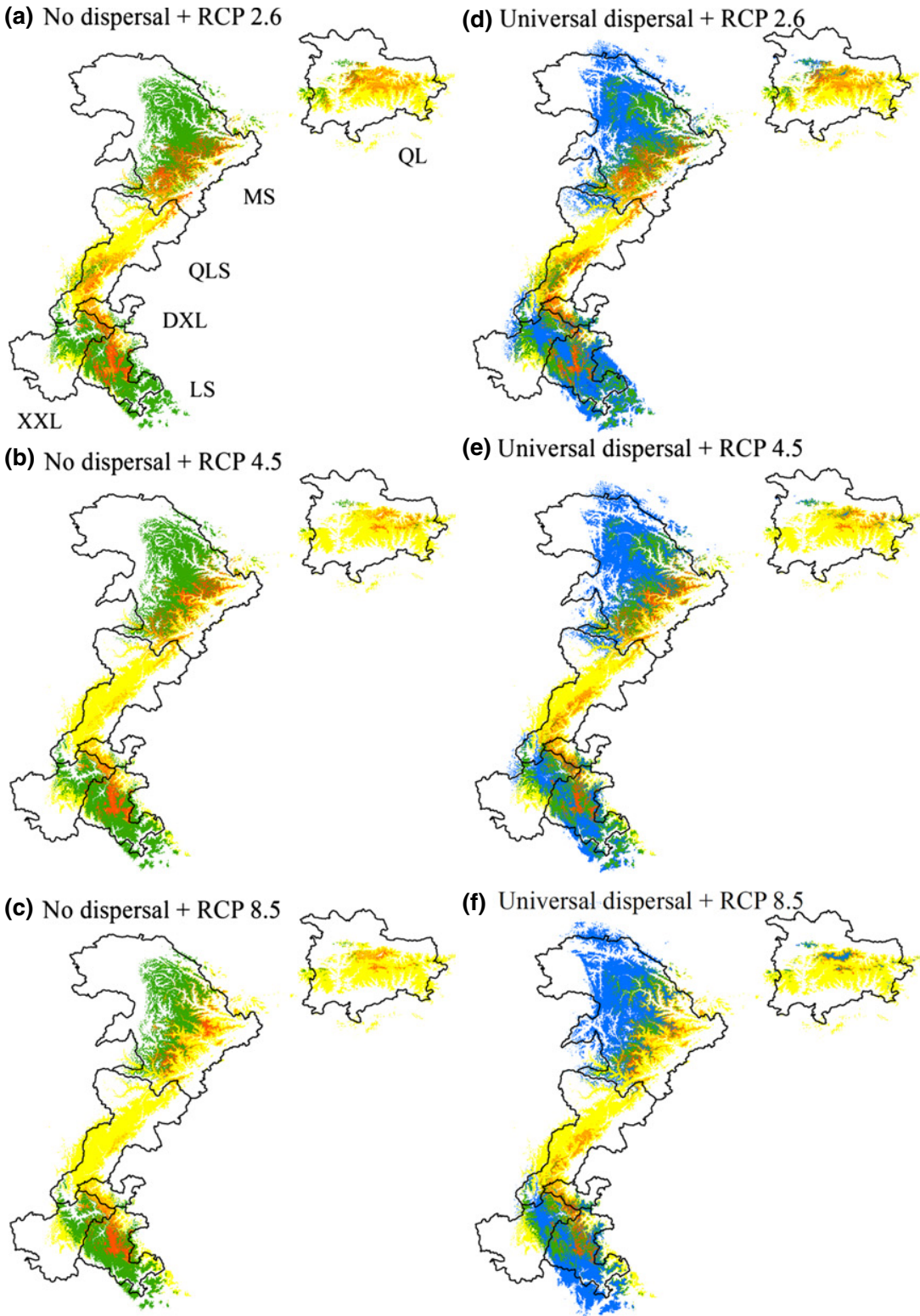

(e) Universal dispersal + RCP 4.5
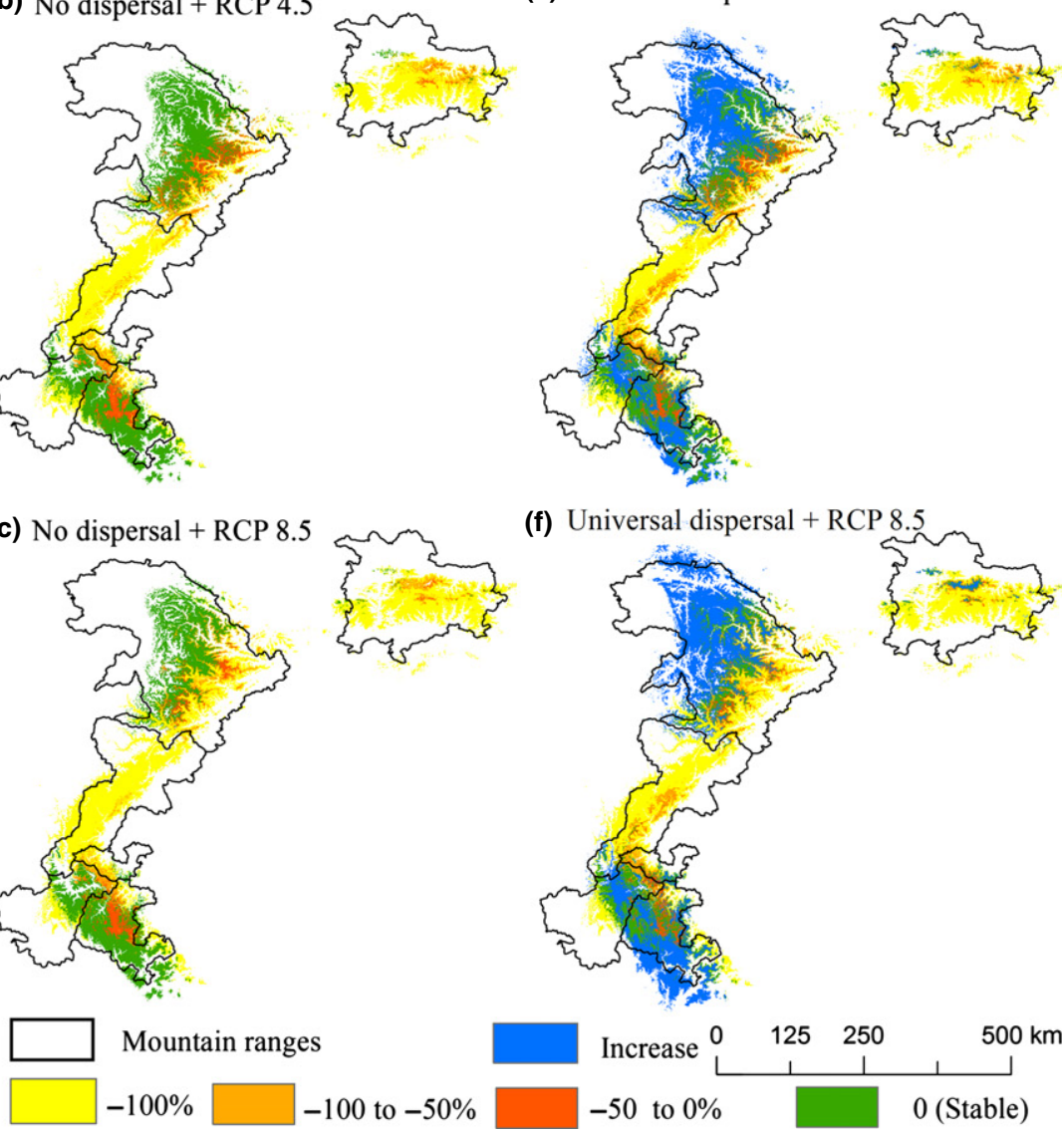

Figure 2 The projected spatial patterns of changes in bamboo species richness (alpha diversity) of bamboo forests between the current and 2070 in the six mountain ranges under the assumption of no dispersal for RCP 2.6 (a), RCP 4.5 (b) and RCP 8.5 (c), and under the assumption of universal dispersal for RCP 2.6 (d), RCP 4.5 (e) and RCP 8.5 (f) (QL, Qinling Mountains; MS, Minshan Mountains; QLS, Qionglaishan Mountains; DXL, Daxiangling Mountains; XXL, Xiaoxiangling Mountains; LS, Liangshan Mountains).

\section{Changes of bamboo distribution in giant panda reserves}

The amount and diversity of bamboo species within panda reserves determines the food availability of giant pandas. More than 60 giant panda nature reserves have been established for protecting the giant panda in past decades in China, which currently covers about 1.88 million hectares of bamboo forests. Unfortunately, our results indicated that future climate change may dramatically reduce the distribution area of bamboo forest located in these reserves. For the assumption of universal dispersal, the percentage of bamboo forest in these reserves will decrease from the current $56 \%$ to $50 \%, 47 \%$ and $43 \%$ under RCP $2.6,4.5$ and 8.5 , respectively, and it would reduce to $41 \%, 37 \%$ and $32 \%$ for the no dispersal scenario. Consequently, over 40 of the 59 current nature reserves may face bamboo forest loss under both climate scenarios, and some reserves would lose all bamboo distribution (Table 3). We also found that future climate change not only is likely to lead to the reduction of the bamboo distribution area, but a decline in the species diversity will occur in most of the current nature reserves during this century. The proportion of bamboo forests with a single bamboo species in panda reserves under the assumption of universal dispersal would also significantly increase from the current $23 \%$ to $29 \%, 31 \%$, and $37 \%$ for RCP $2.6,4.5$ and 8.5 , respectively. It would increase to $37 \%, 33 \%$ and $38 \%$ for no dispersal. 
Table 2 The area and percentage (compared with the current period) of bamboo forests that are projected to be gained, lost or remain under RCP 2.6, 4.5 and 8.5 for 2070 (unit: million hectares)

\begin{tabular}{|c|c|c|c|c|c|c|c|c|c|c|}
\hline \multirow[b]{3}{*}{ Time period } & \multicolumn{6}{|c|}{ Universal dispersal } & \multicolumn{4}{|c|}{ No dispersal } \\
\hline & \multicolumn{2}{|l|}{ Gain } & \multicolumn{2}{|l|}{ Lost } & \multicolumn{2}{|c|}{ Remain } & \multicolumn{2}{|l|}{ Lost } & \multicolumn{2}{|c|}{ Remain } \\
\hline & Area & $\%$ & Area & $\%$ & Area & $\%$ & Area & $\%$ & Area & $\%$ \\
\hline RCP 2.6 & 1.44 & 21.5 & 1.99 & 29.7 & 4.70 & 70.3 & 2.22 & 33.1 & 4.48 & 66.9 \\
\hline RCP 4.5 & 1.43 & 21.4 & 2.71 & 40.4 & 3.99 & 59.6 & 3.02 & 45.1 & 3.68 & 54.9 \\
\hline RCP 8.5 & 1.73 & 25.8 & 3.23 & 48.2 & 3.47 & 51.8 & 3.58 & 53.5 & 3.12 & 46.5 \\
\hline
\end{tabular}

Figure 3 The projected spatial patterns of changes in bamboo beta diversity of bamboo forests between the current and 2070 in the six mountain ranges under the assumption of no dispersal for RCP 2.6 (a), RCP 4.5 (b) and RCP 8.5 (c), and under the assumption of universal dispersal for RCP 2.6 (d), RCP 4.5 (e) and RCP 8.5 (f). Positive values represent increments in species richness, and negative values imply decrements.

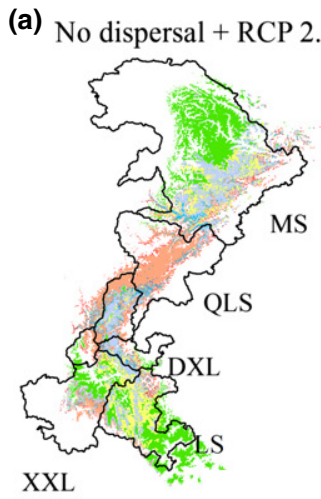

(b) No dispersal + RCP 4.5

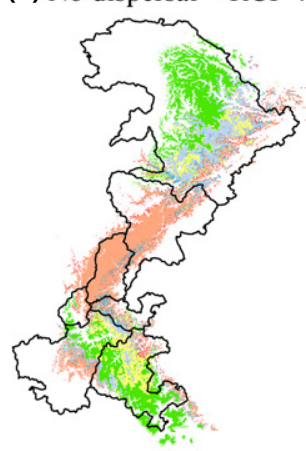

(c) No dispersal + RCP 8
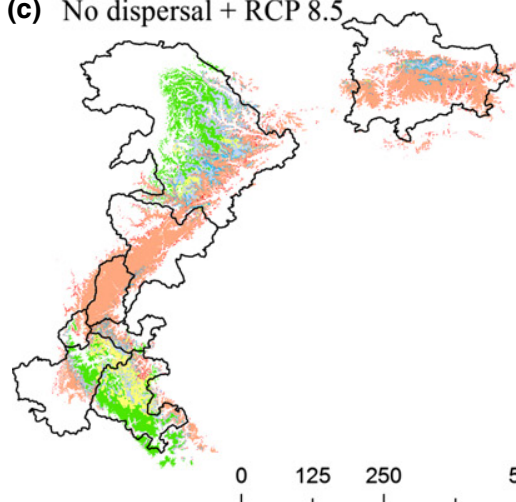

QL (d)
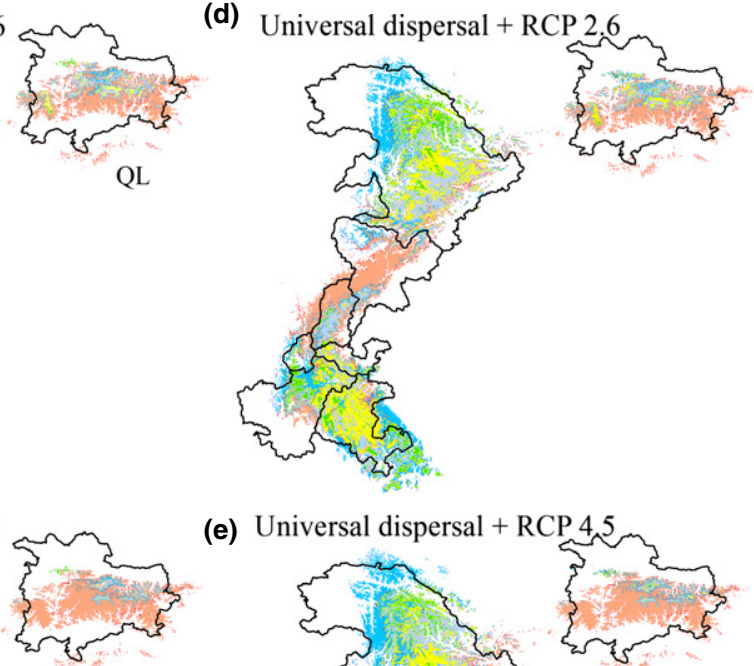

(e) Universal dispersal + RCP 45
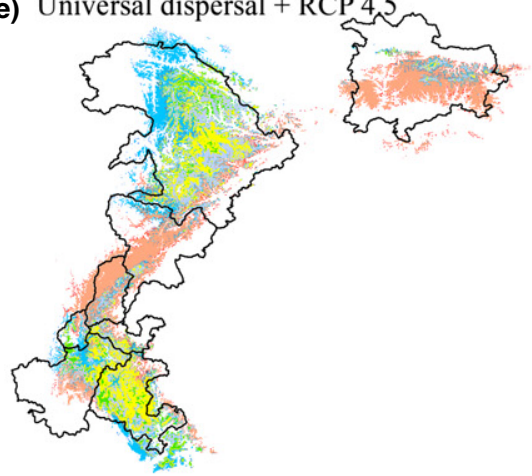

(f) Universal dispersal + RCP 8.5

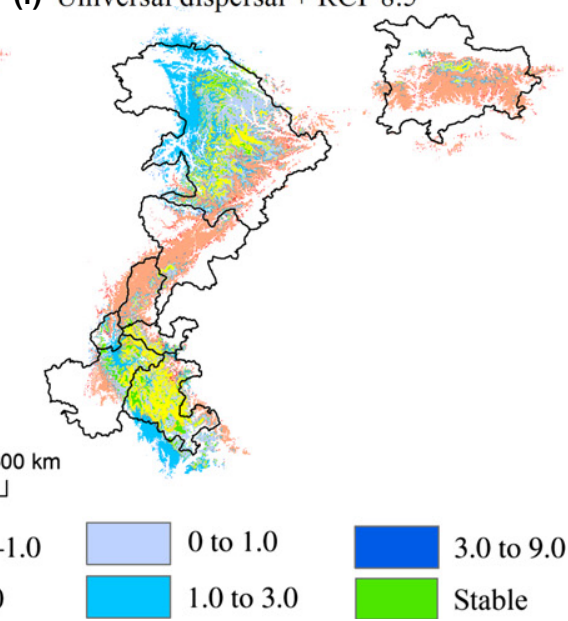



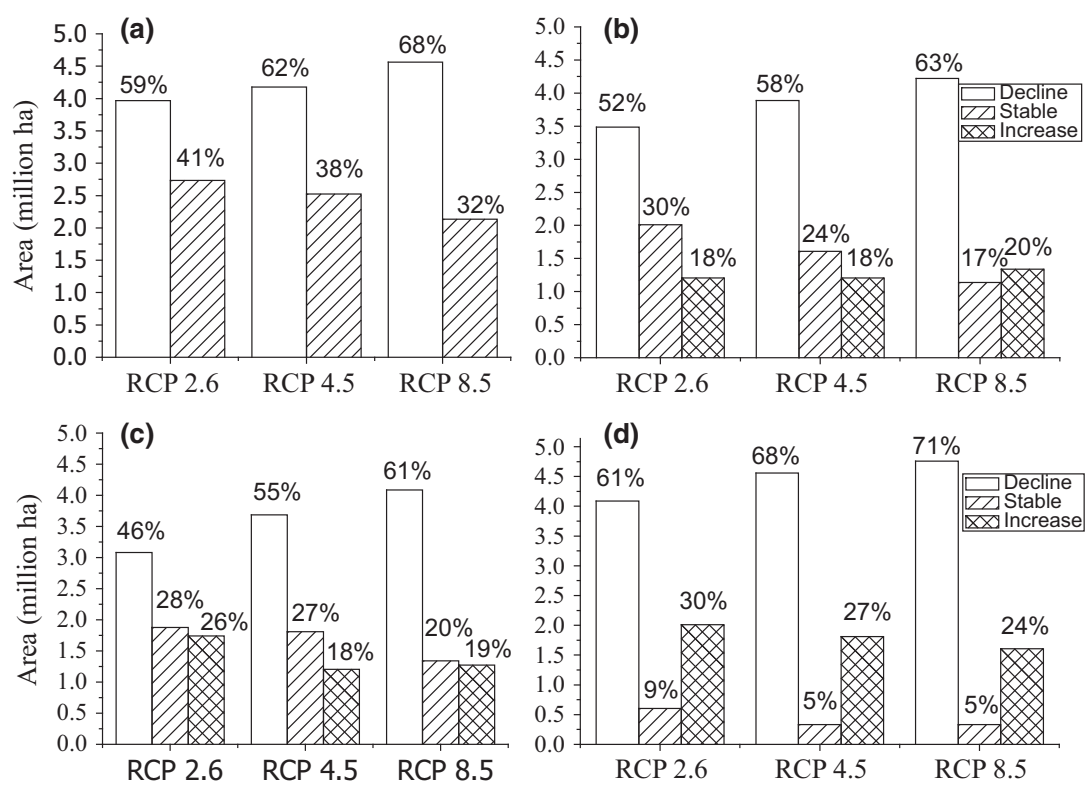

Figure 4 The area and percentage of bamboo forests with species diversity projected to experience decline, increase or stable by 2070 under the three RCPs $(2.6,4.5$ and 8.5$)$ relative to the current bamboo forests: (a) alpha diversity for no dispersal, (b) alpha diversity for universal dispersal, (c) beta diversity for no dispersal and (d) beta diversity for universal dispersal.

Table 3 The projected numbers of giant panda reserves with different percentage of bamboo forest loss (or gain) under the three RCPs by 2070 ( $A$ is the percentage change in bamboo forest area. Negative values represent bamboo forest loss within the reserves)

\begin{tabular}{lcccccccc}
\hline & \multicolumn{3}{l}{ No dispersal } & & \multicolumn{3}{c}{ Universal dispersal } \\
\cline { 2 - 4 } \cline { 7 - 9 } Percentage & RCP & RCP & RCP & & RCP & RCP & RCP \\
change of area & 2.6 & 4.5 & 8.5 & & 2.6 & 4.5 & 8.5 \\
\hline$A=-100$ & 5 & 7 & 12 & & 4 & 5 & 8 \\
$-100<A \leq-50$ & 11 & 15 & 12 & & 15 & 14 \\
$-50<A \leq 0$ & 44 & 37 & 35 & & 30 & 20 & 26 \\
$A>0$ & 0 & 0 & 0 & & 17 & 19 & 11 \\
Total & 59 & 59 & 59 & 59 & 59 & 59 \\
\hline
\end{tabular}

\section{DISCUSSION}

Future changes of bamboo distribution are closely related to the rapid changes of both temperature and precipitation. Meteorological data show that climate in the giant panda habitat has become warmer and drier in past decades (Liu et al., 2004; Wang et al., 2010). The five CMIP5 GCMs also predicted that the climate for this region would continue to become warmer and drier in future (Table S4). Although annual precipitation may increase in most parts of the region (Liu et al., 2005), our results derived from the De Martonne (1926) aridity index suggested that the region would become drier because the warmer temperature would stimulate more evapotranspiration (Figure S5). The climate projections also show that the most rapid increases in temperature and aridity would occur at Qinling, Qionglaishan and Liangshan Mountains where the most severe losses of bamboo forests are projected to occur. As bamboo species generally prefer mild and humid climate conditions ( $\mathrm{Hu}, 2001)$, most of the current bamboo habitats would no longer be climatically suitable in future. The impact of climate change is further aggravated by the poor dispersal ability of bamboo species, which prevents them from colonizing new climatically suitable habitats outside their current ranges. The projections produced by this study and Tuanmu et al. (2013) have suggested that some of the bamboo species may face local extinction under future climate change, especially at Qingling and Qionglaishan Mountains where more serious food shortages are expected for giant pandas in future. Therefore, translocation of giant pandas with small populations (Swaisgood et al., 2010) to the northwestern regions of the current distribution range, where climate change promotes bamboo growth and distributions, may become necessary.

In response to the projected loss of the bamboo forests, an important climate change adaptation strategy for giant panda conservation is to secure their future food source, the bamboo forests. Most of the panda feeding bamboo species are scattered in the lower regions of subalpine forests (Zhang et al., 2011). Protecting the forests, especially the old-growth natural forests, is critical to maintaining suitable habitats for various bamboo species. In areas where the natural forests were cleared, forest restoration efforts should be encouraged, especially in nature reserves. In fact, many restoration projects have been implemented in the region in the past decades, but most of the plantations are monocultures that are not ideal for bamboo species to colonize or grow. Naturalization of these plantations through management techniques is therefore critical to the restoration and conservation of bamboo species. Furthermore, planting bamboo, or assisted migration, could be a potentially important adaptive strategy to reduce the vulnerability of bamboo and the giant panda to future climate change. Planting bamboo can be carried out in new climatically suitable areas outside their current range to compensate for their poor dispersal 
ability. Our projection results under the assumption of universal dispersal can be used to identify the new climatically suitable areas for bamboo planting. Despite that, feasibility studies and impact assessments of such planting activities must be carried out prior to any large-scale implementation.

Bamboo species diversity is projected to significantly decline under future climate change for the three RCPs in this region (Fig. 4). The significant reduction in beta diversity in most of the current bamboo forests represents a general pattern of homogenization in bamboo communities. The decline of both alpha and beta diversity suggests that giant pandas have less chances to choose more bamboo species as their diet in future. This has important implications on giant panda conservation because it would pose a serious threat to the food availability of giant pandas. Sexual reproduction of bamboos occurs once every 60-120 years through flowering, and most bamboos die soon after flowering (Qing, 1989). It usually takes 8-10 years for the bamboo forest to recover post-flowering (Wang, 2006). Large-scale bamboo flowering has been disastrous to the giant panda. For example, the mass flowerings in the 1975 and 1983 have caused the death of more than 270 giant pandas from starvation in the Minshan Mountains alone (Feng, 1991). Climate change may also threaten giant pandas' food supply through increasing the frequency of mass flowering of bamboos (Wang, 2006).The projected warmer and drier climate in this region could accelerate bamboo flowering in future (Qing, 1989). Previous studies found that different bamboo species usually have different flowering cycles according to different environmental conditions ( $\mathrm{Liu} \& \mathrm{Fu}, 2007$; Wang et al., 2010), which makes bamboo species diversity of particular importance in stabilizing the food supply for giant pandas by avoiding simultaneous flowering in the same region. In the Piankou Nature Reserve, for example, there are three bamboo species distributed in slightly different altitude ranges. Two of the species flowered in 2004, forcing the giant pandas to venture into lower altitudes to feed on the remaining species. Therefore, we should pay more attention to climate change-induced reduction in bamboo species diversity in addition to the loss of habitat area. Planting a variety of bamboo species in new climatically suitable areas and maintaining diversity of current bamboo forests are increasingly important for ensuring food security of the giant pandas under climate change.

Although our models indicate good predictive ability, there are several sources of uncertainties in applying current species-climate relationships to future climate conditions. Firstly, future distribution of bamboo species will be influenced by many factors other than climate factors, including human development and catastrophic events (e.g. extreme weather, wildfire and earthquake) that cannot be incorporated into our current predictive models. These events may have profound effects on the distributions of bamboo forests. For example, the earthquake in May 2008 caused a loss of $23 \%$ of giant panda habitats in the southern Minshan Mountains (Xu et al., 2009). Secondly, the probability of mass bamboo flowering was also not considered in our models, even though it could lead to severe loss of bamboo forests sometime in future. Further studies on understanding the timing and mechanisms of bamboo flowering are needed before we can include the flowering impacts into our models. Thirdly, biotic variables are not incorporated in our models, which may include biotic interactions between bamboo species and tree species, aboveground and belowground herbivores, and other resource competitors. These factors could impose additional threats to bamboo species and could exacerbate the impact of climate change. Meanwhile, our results could also overestimate the climate change risk on bamboo species. Our model cannot account for acclimation and adaptation of different bamboo species to future climate change. In reality, evolution and adaptation of bamboo species could be rapid and potentially help them counter stressful conditions or realize ecological opportunities arising from climate change. Thus, a future direction for improving predictive accuracy should incorporate evolutionary considerations in predictive modelling or explore the climate adaptive capacity of bamboo species to climate change. A further uncertainty associated with giant pandas' food is that giant pandas may find other bamboo species as their staple diet in future beyond the current distribution areas of giant pandas, such as in low-altitude and southern areas. Yet, given that the dispersal ability of bamboo species is very poor, they are unlikely to become the staple food sources for giant pandas within the next 100 years. Despite these uncertainties, we have provided comprehensive insights and identified threats for most of bamboo species in panda habitats, which highlighted the need for humanassisted adaptation to climate change for the bamboo species to ensure sustainable food supply for the giant panda in future.

\section{ACKNOWLEDGEMENTS}

We thank Dr. Zhanqiang Wen for assistance in data collections. We thank Dr. Yumin Yang and Prof. Lixin Shen for giving advice on bamboo root growth and flowering. We also thank Yongcheng Long for their comments on the draft of manuscript. Comments from three anonymous referees were extremely valuable for improving earlier drafts of the manuscript. This study is funded by the Project on Promoting New Rural Construction with Science and Technology in Qinghai Province (2013-N-556), the Forestry Department of Sichuan Province (Forest Carbon Monitoring and Accounting Project, 2009-204) and the EU-China Biodiversity Program.

\section{REFERENCES}

Akcakaya, H.R., Butchart, S.H.M., Mace, G.M.S., Stuart, N. \& Hilton-Taylor, C. (2006) Use and misuse of the IUCN Red List Criteria in projecting climate change impacts on biodiversity. Global Change Biology, 12, 2037-2043. 
Allouche, O., Tsoar, A. \& Kadmon, R. (2006) Assessing the accuracy of species distribution models: prevalence, kappa and the true skill statistic (TSS). Journal of Applied Ecology, 43, 1223-1232.

Araújo, M.B. \& New, M. (2007) Ensemble forecasting of species distributions. Trends in Ecology and Evolution, 22, 42-47.

Araújo, M.B. \& Rahbek, C. (2006) How does climate change affect biodiversity? Science, 313, 1396-1397.

Araújo, M.B. \& Williams, P.H. (2000) Selecting areas for species persistence using occurrence data. Biological Conservation, 96, 331-345.

Araújo, M.B., Thuiller, W. \& Pearson, R.G. (2006) Climate warming and the decline of amphibians and reptiles in Europe. Journal of Biogeography, 33, 1712-1728.

Bakkenes, M., Alkemade, J.R.M., Ihle, F., Leemans, R. \& Latour, J.B. (2002) Assessing effects of forecasted climate change on the diversity and distribution of European higher plants for 2050. Global Change Biology, 8, 390-407.

Bellard, C., Bertelsmeier, C., Leadley, P., Thuiller, W. \& Courchamp, F. (2012) Impacts of climate change on the future of biodiversity. Ecology Letters, 15, 365-377.

Boulangeat, I., Gravel, D. \& Thuiller, W. (2012) Accounting for dispersal and biotic interactions to disentangle the drivers of species distributions and their abundances. Ecology Letters, 15, 584-593.

Brooke, L.B., VanDerWal, J., Williams, S.E. \& Johnso, C.N. (2012) Biotic interactions influence the projected distribution of a specialist mammal under climate change. Diversity Distributions, 18, 861-872.

Byrne, M. (2008) Evidence for multiple refugia at different time scales during Pleistocene climatic oscillations in southern Australia inferred from phylogeography. Quaternary Science Reviews, 27, 2576-2585.

Chen, I.C., Hill, J.K., Ohlemüller, R., Roy, D.B. \& Thomas, C.D. (2011) Rapid range shifts of species associated with high levels of climate warming. Science, 333, 1024-1026.

Davis, A.J., Jenkinson, L.S., Lawton, J.H., Shorrocks, B. \& Wood, S. (1998) Making mistakes when predicting shifts in species range in response to global warming. Nature, 391, 783-786.

De Martonne, E. (1926) Aérisme et indice d'aridité. Comptes Rendus de l'Académie des Sciences, 182, 1395-1398.

Duckett, P.E., Wilson, P.D. \& Stow, A.J. (2013) Keeping up with the neighbours: using a genetic measurement of dispersal and species distribution modelling to assess the impact of climate change on an Australian arid zone gecko (Gehyrav ariegata). Diversity and Distributions, 19, 964-976.

Fan, H.H. (1999) Study on rhizome growth regularity of new-planted Phyllostachys edulis. Journal of Fujian College of Forestry, 19, 30-32.

Fan, J., Li, J., Xia, R., Hu, L., Wu, X. \& Li, G. (2014) Assessing the impact of climate change on the habitat distribution of the giant panda in the Qinling Mountains of China. Ecological Modelling, 274, 12-20.

Feng, W.H. (1991) Research papers on Giant panda. Journal of Sichuan University, 3, 7-13.
Fielding, A.H. \& Bell, J.F. (1997) A review of methods for the assessment of prediction errors in conservation presence/ absence models. Environmental Conservation, 24, 38-49.

Gallagher, R.V., Hughes, L. \& Leishman, M.R. (2013) Species loss and gain in communities under future climate change: consequences for functional diversity. Ecography, 36, 531-540.

Golicher, D.J., Cayuela, L. \& Newton, A.C. (2012) Effects of climate change on the potential species richness of Mesoamerican forests. Biotropica, 44, 284-293.

Grassein, F., Lavorel, S. \& Till-Bottraud, I. (2014) The importance of biotic interactions and local adaptation for plant response to environmental changes: field evidence along an elevational gradient. Global Change Biology, 20, 1452-1460.

Hannah, L., Midgley, G.F. \& Millar, D. (2002) Climate change integrated conservation strategies. Global Ecology and Biogeography, 11, 485-495.

Heikkinen, R.K., Luoto, M., Araújo, M.B., Virkkala, R., Thuiller, W. \& Sykes, M.T. (2006) Methods and uncertainties in bioclimatic envelope modelling under climate change. Progress in Physical Geography, 30, 751-777.

Hijmans, R.J. \& Graham, C.H. (2006) The ability of climate envelope models to predict the effect of climate change on species distributions. Global Change Biology, 12, 22722281.

Hijmans, R.J., Cameron, S.E.J., Parra, L., Jones, P.G. \& Jarvis, A. (2005) Very high resolution interpolated climate surfaces for global land areas. International Journal of Climatology, 25, 1965-1978.

$\mathrm{Hu}$, J.C. (2001) Research on the giant panda. Shanghai Science, Technology and Education Publish House, Shanghai.

Keith, D.A., Akcakaya, H.R., Thuiller, W., Midgley, G.F., Pearson, R.G., Phillips, S.J., Regan, H.M., Araujo, M.B. \& Rebelo, T.G. (2008) Predicting extinction risks under climate change: coupling stochastic population models with dynamic bioclimatic habitat models. Biology Letters, 4, 560-563.

Kissling, W.D., Field, R., Korntheuer, H., Heyder, U. \& Bohning-Gaese, K. (2010) Woody plants and the prediction of climate-change impacts on bird diversity. Philosophical Transactions of the Royal Society B: Biological Sciences, 365, 2035-2045.

Li, W.K. \& Guo, Q.H. (2013) How to assess the prediction accuracy of species presence-absence models without absence data? Ecography, 36, 788-799.

Liu, Y.Y. \& Fu, J.H. (2007) Bamboo in habitat of giant panda and its flowering phenomenon. World Bamboo and Rattan, 5, 1-4.

Liu, J.G., Linderman, M., Ouyang, Z.Y., An, L., Yang, J. \& Zhang, H.M. (2001) Ecological degradation in protected areas: the case of Wolong Nature Reserve for giant pandas. Science, 292, 98-101.

Liu, B.H., Xu, M., Henderson, M., Qi, Y. \& Li, Y.Q. (2004) Taking China's temperature: daily range, warming trends, and regional variations, 1955-2000. Journal of Climate, 17, 4453-4462. 
Liu, B.H., Xu, M., Henderson, M. \& Qi, Y. (2005) Observed trends of precipitation amount, frequency, and intensity in China, 1960-2000. Journal of Geophysical Research, 110, $1-10$.

Lobo, J.M., Jiménez-Valverde, A. \& Real, R. (2008) AUC: a misleading measure of the performance of predictive distribution models. Global Ecology and Biogeography, 17, 145151.

Loucks, C.J., Lv, Z., Dinerstein, E., Wang, H., Olson, D.M., Zhu, C. \& Wang, D. (2001) Giant Pandas in a changing landscape. Science, 294, 1465.

MacLean, I.M.D. \& Wilson, R.J. (2011) Recent ecological responses to climate change support predictions of high extinction risk. Proceedings of the National Academy of Sciences USA, 108, 12337-12342.

Menendez, R., Gonzalez-Megias, A., Collingham, Y., Fox, R., Roy, D.B., Ohlemuller, R. \& Thomas, C.D. (2007) Direct and indirect effects of climate and habitat factors on butterfly diversity. Ecology, 88, 605-611.

Midgley, G.F., Hannah, L., Millar, D., Thuiller, W. \& Booth, A. (2003) Developing regional and species-level assessments of climate change impacts on biodiversity: a preliminary study in the Cape Floristic Region. Biological Conservation, 112, 87-97.

Mokany, K. \& Ferrier, S. (2011) Predicting impacts of climate change on biodiversity: a role for semi-mechanistic community-level modeling. Diversity and Distributions, 17, 374-380.

Ochoa-Ochoa, L.M., Rodríguez, P., Mora, F., Flores-Villela, O. \& Whittaker, R.J. (2012) Climate change and amphibian diversity patterns in Mexico. Biological Conservation, 150, 94-102.

Pearson, R.G. \& Dawson, T.P. (2003) Predicting the impacts of climate change on the distribution of species: are bioclimate envelope models useful? Global Ecology and Biogeography, 12, 361-371.

Pearson, R., Raxworthy, C., Nakamura, M. \& Peterson, A. (2007) Predicting species distributions from small numbers of occurrence records: a test case using cryptic geckos in Madagascar. Journal of Biogeography, 34, 102-117.

Peery, M.Z., Becker, B.H. \& Beissinger, S.R. (2006) Combining demographic and count-based approaches to identify source-sink dynamics of a threatened seabird. Ecological Applications, 16, 1516-1528.

Peterson, A.T., Ortega-Huerta, M.A., Bartley, J., SánchezCordero, V., Soberón, J., Buddemeier, R.H. \& Stockwell, D.R.B. (2002) Future projections for Mexican faunas under global climate change scenarios. Nature, 416, 626-629.

Phillips, S.J., Anderson, R.P. \& Schapire, R.E. (2006) Maximum entropy modeling of species geographic distributions. Ecological Modelling, 190, 231-259.

Ponce-Reyes, R., Reynoso-Rosales, V.H., Watson, J.E.M., VanDerWal, J., Fuller, R.A., Pressey, R.L. \& Possingham, H.P. (2012) Vulnerability of cloud forest reserves in Mexico to climate change. Nature climate change, 2, 448-452.
Ponce-Reyes, R., Nicholson, E., Baxter, P.W.J., Fuller, R. \& Possingham, H. (2013) Extinction risk in cloud forest fragments under climate change and habitat loss. Diversity and Distributions, 19, 518-529.

Preston, K.L., Rotenberry, J.T., Redak, R.A. \& Allen, M.F. (2008) Habitat shifts of endangered species under altered climate conditions: importance of biotic interactions. Global Change Biology, 14, 2501-2515.

Qing, Z.S. (1989) Statistic analysis of the environmental effect upon the flowering of Baishaniafangian. Journal of Sichuan Normal University, 10, 36-44.

Ran, J., Du, B. \& Yue, B. (2009) Conservation of the endangered giant panda ailuropoda melanoleuca in China: successes and challenges. Oryx, 43, 176-178.

Rebelo, H., Tarrosow, P. \& Jones, G. (2010) Predicted impact of climate change on European bats in relation to their biogeographic patterns. Global Change Biology, 16, 561-576.

Schwartz, M.W., Iverson, L.R., Prasad, A.M., Matthews, S.N. \& O'Connor, R.J. (2006) Predicting extinctions as a result of climate change. Ecology, 87, 1611-1615.

Scoble, J. \& Lowe, A.J. (2010) A case for incorporating phylogeography and landscape genetics into species distribution modelling approaches to improve climate adaptation and conservation planning. Diversity and Distributions, 16, 343-353.

Shen, G.Z., Feng, C.Y., Xie, Z.Q., OuYang, Z.Y., Li, J.Q. \& Pascal, M. (2008) Proposed conservation landscape for giant pandas in the Minshan Mountains, China. Conservation Biology, 22, 1144-1153.

Srivastava, D.S. (1999) Using local-regional richness plots to test for species saturation: pitfalls and potentials. Journal of Animal Ecology, 68, 1-16.

State Forestry Administration (2006) The third national survey report on giant panda in China. Science Press, Beijing.

Swaisgood, R.R., Wei, F.W., Wildt, D.E., Kouba, A.J. \& Zhang, Z.J. (2010) Giant panda conservation science: how far we have come. Biology Letters, 6, 143-145.

Synes, N.W. \& Osborne, P.E. (2011) Choice of predictor variables as a source of uncertainty in continental-scale species distribution modelling under climate change. Global Ecology and Biogeography, 20, 904-914.

Thomas, C.D., Cameron, A., Green, R.E., Bakkenes, M., Beaumont, L.J., Collingham, Y.C., Erasmus, B.F.N., de Siqueira, M.F., Grainger, A., Hannah, L., Hughes, L., Huntley, B., Jaarsveld, A.S.V., Midgley, G.F., Miles, L., OrtegaHuerta, M.A., Peterson, A.T., Phillips, O.L. \& Williams, S.E. (2004) Extinction risk from climate change. Nature, 427, 145-148.

Thuille, W. (2007) Climate change and the ecologist. Nature, 448, 550-552.

Thuiller, W., Araújo, M.B. \& Lavorel, S. (2004) Do we need land-cover data to model species distributions in Europe? Journal of Biogeography, 31, 353-361.

Thuiller, W., Lavorel, S., Araujo, M.B., Sykes, M.T. \& Prentice, I.C. (2005) Climate change threats to plant diversity 
in Europe. Proceedings of the National Academy of Sciences USA, 102, 8245-8250.

Thuiller, W., Midgley, G., Hughes, G.O., Bomhard, B., Drew, G., Rutherford, M.C. \& Woodward, F.I. (2006a) Endemic species and ecosystem sensitivity to climate change in Namibia. Global Change Biology, 12, 759-776.

Thuiller, W., Lavorel, S., Skyes, M.T. \& Araújo, M.B. (2006b) Using niche-based modelling to assess the impact of climate change on tree functional diversity in Europe. Diversity and Distributions, 12, 49-60.

Tuanmu, M.N., Viña, A., Winkler, J.A., Li, Y., Xu, W.H., Ouyang, Z.Y. \& Liu, J.G. (2013) Climate-change impacts on understorey bamboo species and giant pandas in China's Qinling Mountains. Nature Climate Change, 3, 249253.

VanDerWal, J., Shoo, L.P., Graham, C. \& Williams, S.E. (2009) Selecting pseudo-absence data for presence-only distribution modeling: how far should you stray from what you know? Ecological Modelling, 220, 589-594.

Vos, C.C., Berry, P., Opdam, P., Baveco, H., Nijhof, B., O'Hanley, J., Bell, C. \& Kuipers, H. (2008) Adapting landscapes to climate change: examples of climate-proof ecosystem networks and priority adaptation zones. Journal of Applied Ecology, 45, 1722-1731.

Walther, G.R., Post, E., Convey, P., Menze, A., Parmesan, C., Beebee, T.J.C., Fromentin, J.M., Hoegh-Guldberg, O. \& Bairlein, F. (2002) Ecological responses to recent climate change. Nature, 416, 389-395.

Wang, X.H. (2006) Study on the influence of environmental factors on bamboo bloom. Sichuan Journal of Zoology, 28, 618-621.

Wang, R.T., Fan, X., Liu, Q. \& Chen, W.X. (2010) Impacts of climate change on giant Panda habitat in Sichuan. Plateau and Mountain Meteorology Research, 4, 57-60.

Wardle, D.A., Bardgett, R.D., Callaway, R.M. \& Van der Putten, W.H. (2011) Terrestrial ecosystem responses to species gains and losses. Science, 332, 1273-1277.

Wiens, J.J. \& Graham, C.H. (2005) Niche conservatism: integrating evolution, ecology, and conservation biology. Annual Review of Ecology and Systematics, 36, 519-539.

Wong, M.H.G., Li, R.Q., Xu, M. \& Long, Y.C. (2013) An integrative approach to assessing the potential impacts of climate change on the Yunnan snub-nosed monkey. Biological Conservation, 158, 401-409.

Wu, R.D., Zhang, S., Yu, D.W., Zhao, P., Wang, L.Z., Yu, Q., Ma, J., Chen, A. \& Long, Y.C. (2011) Effectiveness of China's nature reserves in representing ecological diversity. Frontiers in Ecology and the Environment, 9, 383-389.

Xu, W.H., Wang, X.Z., Ouyang, Z.Y., Zhang, J.D., Li, Z.Q., Xiao, Y. \& Zheng, H. (2009) Conservation of giant panda habitat in South Minshan, China, after the May 2008 earthquake. Frontiers in Ecology and the Environment, 7, 353-358.

Yang, X. \& Xu, M. (2003) Biodiversity conservation in Changbai Mountain Biosphere Reserve, northeastern China status, problem, and strategy. Biodiversity and Conservation, 12, 883-903.

Zhang, Z.J., Swaisgood, R.R., Zhang, S., Nordstrom, L.A., Wang, H.J., Gu, X.D., Hu, J.C. \& Wei, F.W. (2011) Oldgrowth forest is what giant pandas really need. Biology Letters, 7, 403-406.

\section{SUPPORTING INFORMATION}

Additional Supporting Information may be found in the online version of this article:

Table S1 Test omission rates (OR) at the $10 \%$ cumulative threshold, area under the receiver operating characteristic curve (AUC), test gains and true skill statistic (TSS) for the 16 bamboo species distribution models.

Table S2 The population size and density in six Mountain Ranges from the Third National Survey on Giant Panda.

Table S3 Bioclimatic variables considered in in the distribution models of the 16 bamboo species.

Table S4 Projected average change (minimum, maximum) of future (average for 2061-2080) from current (1950-2000) climate conditions for the five GCMs under the three RCPs for the study area.

Figure S1 Simulated occurrence probability of 16 bamboo species based on the ensemble forecast (the mean probability, the minimum probability, the maximum probability) from MAxEnT model outputs under five GCMs (CC, CN, HE, MC, MP) for RCCP 4.5 in 2070 in giant panda habitats in six Mountain Ranges (Qingling, Minshan, Qionglaishan, Daxiangling, Xiaoxiangling, and Liangshan) in China.

Figure S2 The projected spatial patterns of bamboo species richness (alpha diversity) of bamboo forests in the six mountain ranges under the assumption of no dispersal for RCP 2.6 (a), RCP 4.5 (b), and RCP 8.5 (c), and under the assumption of universal dispersal for RCP 2.6 (d), RCP 4.5 (e), and RCP 8.5 (f) (QL, Qinling Mountains; MS, Minshan Mountains; QLS, Qionglaishan Mountains; DXL, Daxiangling Mountains; XXL, Xiaoxiangling Mountains; LS, Liangshan Mountains).

Figure S3 The projected area and proportion of bamboo forests with different species richness in the study area in current period and 2070 under the three RCPs (2.6, 4.5 and 8.5) assuming universal dispersal and no dispersal.

Figure S4 The projected spatial patterns of bamboo beta diversity of bamboo forests in the six mountain ranges under the assumption of no dispersal for RCP 2.6 (a), RCP 4.5 (b), and RCP 8.5 (c), and under the assumption of universal dispersal for RCP 2.6 (d), RCP 4.5 (e), and RCP 8.5 (f) (QL, Qinling Mountains; MS, Minshan Mountains; QLS, Qionglaishan Mountains; DXL, Daxiangling Mountains; XXL, Xiaoxiangling Mountains; LS, Liangshan Mountains). 
Figure S5 Projected changes of future De Martonne aridity index (average for 2061-2080) for the five GCMs (MPIESM-LR: MP, MIROC5: MI; HadGEM2-ES: HE; CNRMCM5: CN; CCSM4: CC) under the three RCPs (2.6, 4.5 and 8.5) from current (1950-2000) climate conditions for the study area.

\section{BIOSKETCH}

Renqiang Li is an assistant professor at Key Laboratory of Ecosystem Network Observation and Modeling (http://english.lenom.igsnrr.cas.cn/), Institute of Geographic Sciences and Natural Resources (IGSNRR), the Chinese Academy of
Sciences (CAS). His current research interests focus on climate change and biodiversity conservation, especially climate change impact, vulnerability, and adaptation. $\mathrm{He}$ is also interested in environmental change and ecosystem services.

Author contributions: R.L., M.X. and M.W. designed the project, collected and analyzed the data, and prepared the manuscript. The fourth and the subsequent authors are contributed equally to this work by joining discussion and assisting data processing.

Editor: Wilfried Thuiller 